\title{
THE APPLICATIONS OF EDGE-DETECTION IMAGE FILTERING IN MEDICAL IMAGING AND DIAGNOSIS
}

\author{
Bogdan Jankowicz
}

\begin{abstract}
Summary
This article presents examples of the use of image filtering for various types of diagnostic medical imaging in order to improve their interpretative value, and thus to improve the diagnostic reliability of that imaging.

As research and visual tests have shown, in many cases, the use of digital image filtering makes it possible to significantly improve not only image quality, but also their readability or clarity, thus contributing to a more accurate and precise reading and interpretation of information contained in the images.

The author proposed specific filters that largely meet the assumed conditions and constitute a supplement, and sometimes introduce a possible new application in addition to those already known in subject literature.

A visual assessment was also made of the degree of diagnostic usefulness of images after filtration compared to the source images.

The most commonly used filters are those that not only help to improve the overall appearance and quality of the image, but also, on the one hand, help to extract or highlight certain information, or to reduce noise, on the other hand. Thanks to these solutions, it is possible to smoothen or sharpen some structures within the images, which impacts their readability and quality. Thus, image filtering has become a very desirable and useful tool in many fields of science, technology, as well as art and medicine. The subject matter of image transformation is here applied to the latter discipline.
\end{abstract}

\section{Keywords}

medical imaging $\bullet$ edge-detection $\bullet$ image filtering $\bullet$ photo-interpretation

\section{Introduction}

Modern imaging technologies have now become an inseparable and basic diagnostic method used in medicine (Fig. 1). Therefore, today it is not only the skills of the doctor - diagnostician, acting as the image interpreter that are important, but also the appropriate equipment and its specific parameters.

In addition, the accuracy of the diagnosis can be facilitated and even improved by the process to which the resulting photos will be subjected. 
The category of medical images seems to be one of the most demanding in terms of fidelity imaging while maintaining high-quality presentation of all relevant details. The methods of processing, quality improvement or compression used here require effective, explicit and objective image quality indicators, preferably in terms of diagnostic value. Averaged measures of a general nature may be insufficient, whereas local indicators and their interpretation are strongly dependent on the frame semantics and the significance of individual structures and their fragments, which poses a problem when striving to improve methods and tools for supporting medical imaging.

In addition, each imaging system has its limitations and not all features of the presented structures are reflected in the recorded images.

Each imaging system has a time-frequency signal transfer function that determines the cut-off frequency, allowing a specific level of detail in the description of information about the objects presented in the recorded image.

The purpose of medical imaging support methods is to increase the diagnostic reliability of images, associated with the detection of pathological symptoms, making a diagnosis, or establishing the course of therapy.

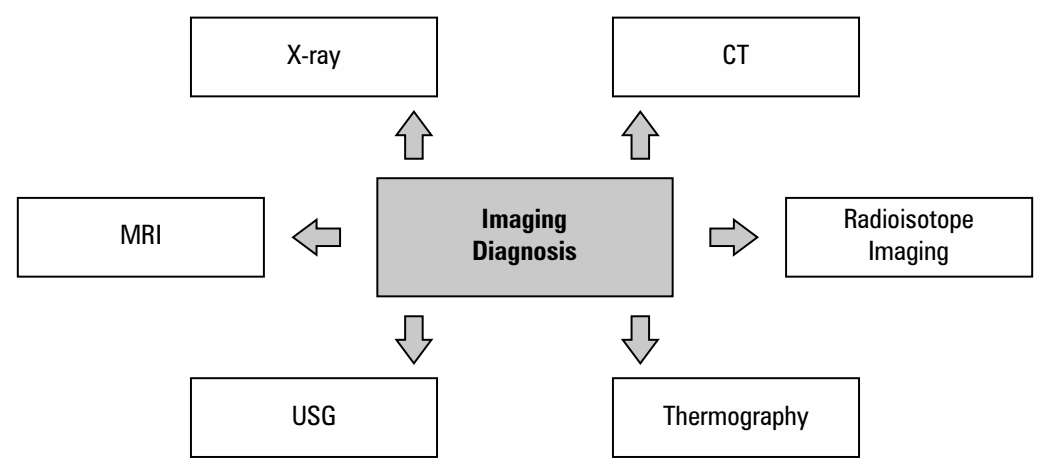

Source: Author's own study

Fig. 1. Types of scans in medical imaging (CT - Computer Tomography/PET - Positron Emission Tomography, MRI - Magnetic Resonance Imaging)

The article presents an analysis of processed digital images based on the use of the image filtering process. It should be noted, that even the most accurate selection of the filter is not going to produce the correct effect if the appropriate imaging method is not chosen. For example, the methods for diagnosing breast cancer - one of the most common cancers - differ in that during ultrasonography (USG), ultrasound waves are used, whereas "mammography" ( mamma - Latin for 'breast', grapho - Greek for 'write') applies X-rays [Shuler and Laine 2003]. In ultrasonography, the image is created as a result of ultrasound reflecting from tissues [Nieniewski and Zajączkowski 2015].

Breast cancer, as well as cancers of other organs, presents as a dark area in ultrasonography, but as a bright area in $\mathrm{x}$-ray imaging - this is particularly clear after performing 
the edge-detection image filtering process, where a more clearly distinguished, sharply rendered, ovoid pathological structure is more pronounced (Fig. 2). Therefore, if we wish that the pathologically changed area be distinguished from healthy tissue, light glandular (younger) tissue should be examined by ultrasound, whereas dark adipose (older) tissue - should be subjected to radiological examination, although in some cases there are exceptions (e.g. with the use of hormone therapy). Unfortunately, one scan is not always sufficient, because mammography does not distinguish solid lesions or nodules from structures containing fluid, such as for instance cysts, while an ultrasound scan captures these differences very efficiently [Periaswamy 1996, Soja 2015].

In the present article, the source material (photo images) was provided by specialists - radiologists, using professional medical equipment appropriate for imaging, then it was processed by the author of the publication, using his own experience and based on knowledge acquired from selected bibliographic items. Therefore the results (image filtering) constitute author's own elaboration. Subject literature on image processing for medical purposes is very abundant, and it is impossible to list all the pertinent works, hence only some of those were selected, sometimes only indirectly related to the subject of the article, not least because of its interdisciplinary character, e.g. [Soja 2009, Tadeusiewicz 2011].

On the other hand, the positron emission tomography (CT-PET) scan, using radioisotope techniques, is ordered for patients suspected of having a malignant tumour, when other diagnostic methods cannot tell where the primary location of the disease was, that is, where it originated. This enables early diagnosis of malignant lesions as well as distinguishing between malignant and benign lesions. Positron emission tomography imaging using the isotope is based on the finding of increased glucose metabolism in cancer cells. In addition, positron emission tomography is ordered for patients after surgical treatment of a malignant tumour, because thanks to the PET scan the attending physician is able to determine whether the surgery was completely successful, as well as whether the complementary, inoperative treatment used (e.g. chemotherapy) is bringing beneficial results and the expected response to treatment [www.doz.pl].
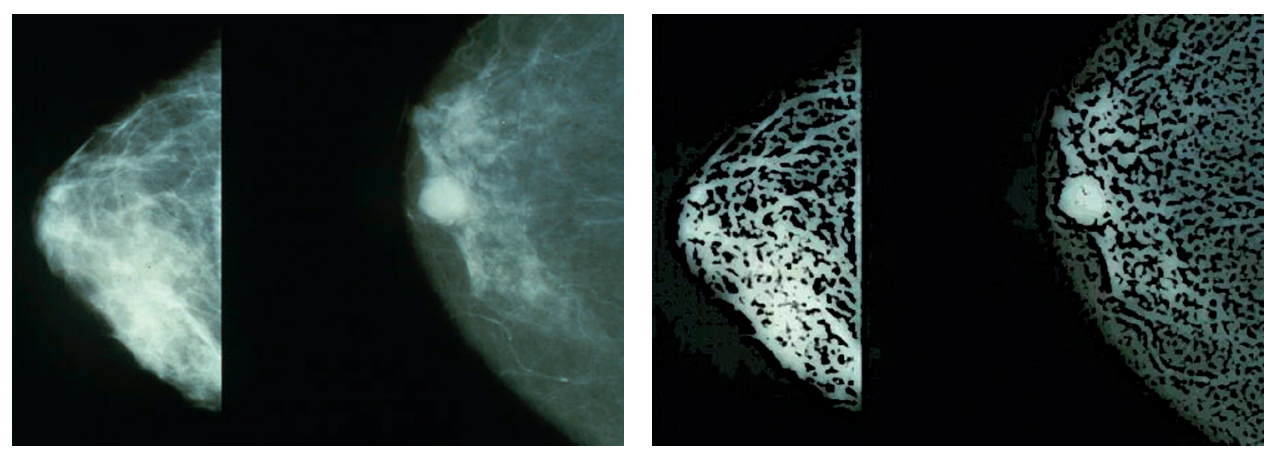

Source: Author's own materials

Fig. 2. A pair of mammographic images (normal and with cancer): before (left) and after edge filtration (on the right, where the imaged structures are distinguished more clearly). 


\section{Studying filters in terms of the level of detectability of objects and structures}

Image filtering is one of the digital signal processing methods. Specifically, it is a mathematical operation on the pixels of the source image, which results in a new, transformed image [Butowtt 2003]. Image filtering is referred to as contextual transformation, because information from multiple pixels of the source image is required in order to determine the new pixel value of the target image.

Image filtering is typically used as a method of extracting a series of information from the original image for further processing. Such information can be, for instance: edge position, object corner positions, etc. Another use of image filtering is noise removal (median filter and others) or image blur (averaging, Gaussian filters). Filtering can be carried out in both spatial and frequency domains. In the spatial domain it is obtained by using convolution operations. In the frequency domain, the equivalent of the convolution is the operation of multiplying image and filter transforms.

The image is defined as a function of two variables $f(p, r)$, where $p$ and $r$ specify spatial coordinates, whereas the value of the function $\mathrm{f}$ for the given $\mathrm{p}$ and $\mathrm{r}$ coordinates is the grey-scale value, denoted by the dimensionless unit DN. If the coordinates $\mathrm{p}$ and $r$ are finite values and the value of the function $f$ is quantized, the resulting image is called a digital image [Dorozhynskyy 2009].

The use of filters to process the image consists in determining a new point value by using the point values from its immediate proximity. The pixels in the immediate proximity contribute during the calculations. This contribution is saved in the structure of the mask, which is then presented in the form of a matrix. Its popular sizes are $3 \times 3$, $5 \times 5$, and $7 \times 7$. The mask format is usually odd, because the centre pixel specifies the pixel for which the mathematical transformation process is performed.

In the next part, image filtering was examined with a $3 \times 3$ filter and its elements marked in the matrix as $\mathbf{f}$ (relative to the central element with the position $[0,0]$ ) [Bołdak 2008]:

$$
\begin{array}{lll}
\mathrm{f}[-1,-1] & \mathrm{f}[0,-1] & \mathrm{f}[1,-1] \\
\mathrm{f}[-1,0] & \mathrm{f}[0,0] & \mathrm{f}[1,0] \\
\mathrm{f}[-1,1] & \mathrm{f}[0,1] & \mathrm{f}[1,1]
\end{array}
$$

The new value of the component of the "a" element with the assumed coordinates ( $p, r$ ) is elaborated according to the presented formula (I). First, it is necessary to calculate the weighted sum of the component - of the particular element and all its neighbouring elements - based on the weight represented by the filter mask (in the case of zero value, we assume that $s=1$ ) [http://astrophysics.fic.uni.lodz.pl/medtech/dodatki/ metpo.html]. 


$$
\begin{gathered}
s=f_{-1,-1} \cdot a_{p-1, r-1}+f_{0,-1} \cdot a_{p, r-1}+f_{1,-1} \cdot a_{p+1, r-1}+f_{-1,0} \cdot a_{p-1, r}+f_{0,0} \cdot a_{p, r}+ \\
+f_{1,0} \cdot a_{p+1, r}+f_{-1,1} \cdot a_{p-1, r+1}+f_{0,1} \cdot a_{p, r+1}+f_{1,1} \cdot a_{p+1, r+1}
\end{gathered}
$$

The resulting sum should then be divided by all the weights of the mask. By applying the process of normalizing the component value, we prevent the brightness of the transformed digital image (II) from changing.

$$
a_{p, r}^{\prime}=\frac{s}{f_{-1,-1}+f_{0,-1}+f_{1,-1}+f_{-1,0}+f_{0,0}+f_{1,0}+f_{-1,1}+f_{0,1}+f_{1,1}}
$$

Image filtering should be applied separately to each image factor, i.e. if the image is represented by an RGB model then the filtering will be carried out for the subsequent $\mathrm{R}, \mathrm{G}$, and B components; for example, it is also possible to select one component from the calculations.

The literature related to the topics discussed in this article is rather extensive. To a greater or lesser extent, also by using certain analogies, it becomes indispensable in solving the problems of not only image filtering, but also of image compression, quality assessment, or the use of wavelet transformation [Pyka 2005, 2007, 2011, 2012].

When studying the literature on the subject, a kind of interesting counter-proposal was formulated, namely, the use of wavelet analysis in the image filtering process albeit with the final effect similar to the one presented in this article, based on image filtering [Kędzierski 2002]. Using an example taken from geodesy and photogrammetry, wavelet analysis can be applied to the search for homologous points in the photo, or even used in the process of filtering aerial photographs or satellite images of earth's surface.

In contemporary digital photogrammetry, an important role is played by the image correlation process, which is used in basic activities at a digital photogrammetric station. If we provide "weak" images for processing, then the image correlation process used in automatic aerotriangulation or in the generation of the Digital Terrain Model will be carried out at a low level of confidence or it may generate erroneous results.

Depending on the method of photo processing (type of image correlation), two ways of using wavelets in the image filtering process can be distinguished:

- the first is the detection of edges in the image structure,

- the second is the facility to remove noise from digital images.

Wavelet analysis applies approximating functions that are located in the time (position) and frequency domains, whereas wavelets are functions that make it possible to split input data into components of different frequencies, and to analyse each element with an accuracy corresponding to the scale of the sample. In practice, the purpose of wavelet analysis is to find the parent wavelet and figure out how to obtain them using numerical methods. 
It is known from the literature on the subject [Kędzierski 2002] that every task using fast Fourier transformation (FFT) can be formulated using wavelets, whilst providing more spatial information about the location and frequency. By applying the wavelet analysis algorithm, we obtain an image containing only the edges of the objects. However, by algebraic addition of the obtained image with edges to the original image, we obtain an image in which the elements used in the process of image correlation by the Feature Based Matching method are significantly enhanced [Sayood 2002]. As a result of this enhancement, errors in the process that applies digital image correlation (FBM) will be significantly reduced. However, it should be noted that in the final result, when using the obtained image, the results may be prone to over-interpretation - hence the application of the described algorithm in this case is not entirely appropriate. In turn, sub-pixel edge detection [Mikrut 2009] and automatic edge detection increase accuracy and work well in technical structures (e.g. for the approximation of edges). In the case of biological structures, this is no longer the case, because of the irregularity of the lines characteristic of the imaged object or structure.

However, in practice, image filtering can be applied directly, and we can define it as a mathematical operation performed on the pixels of a given image, which creates a new, processed image. It is therefore a method of digital signal processing. The results of image filtering depend on the type of filter we use for the purpose. The present author proposes to apply the Laplace filter, as according to comparative visual tests of diagnostic accuracy, it improves the interpretation value, and thus increases diagnostic reliability of the image. According to specialists, the use of Laplace filter makes the process of detecting pathological changes much easier, and often significantly improves it.

Tests of diagnostic accuracy in the case here described were carried out in a simplified way, by comparing the source image with the image after filtering, however, while also taking into account the interpretation principles based on the ROC curve - due to the fact that the purpose of the article is to present new filters rather than an in-depth analysis of diagnostic accuracy for each of the filtered images (Fig. 3).

However, in order to statistically assess the quality and suitability of a particular filter for the purposes of medical imaging and diagnostics - and to do that as dependably and reliably as possible - it would first be necessary to create a profile of each diagnostician participating in the sample, then "order" them by sensitivity (which means performing a separate test to assess the aforementioned "sensitivity") and then ask them to interpret the images in turn, distinguishing between the correctness of the decisions for both the images both "before" and "after" image filtering. At this point, there is a certain risk or bias - that the diagnostician will be influenced by the image that he or she will see first (whether it is before or after image filtering). Therefore, the test carried out in this way is not perfect either. The bias could be avoided by using a sufficiently large number of images to be interpreted, furthermore, of a fairly similar nature, so that the diagnostician would not makes associations between them. The problem is that hardly anyone would agree take part in such an extensive study - hence, the author decided to simplify the research. 


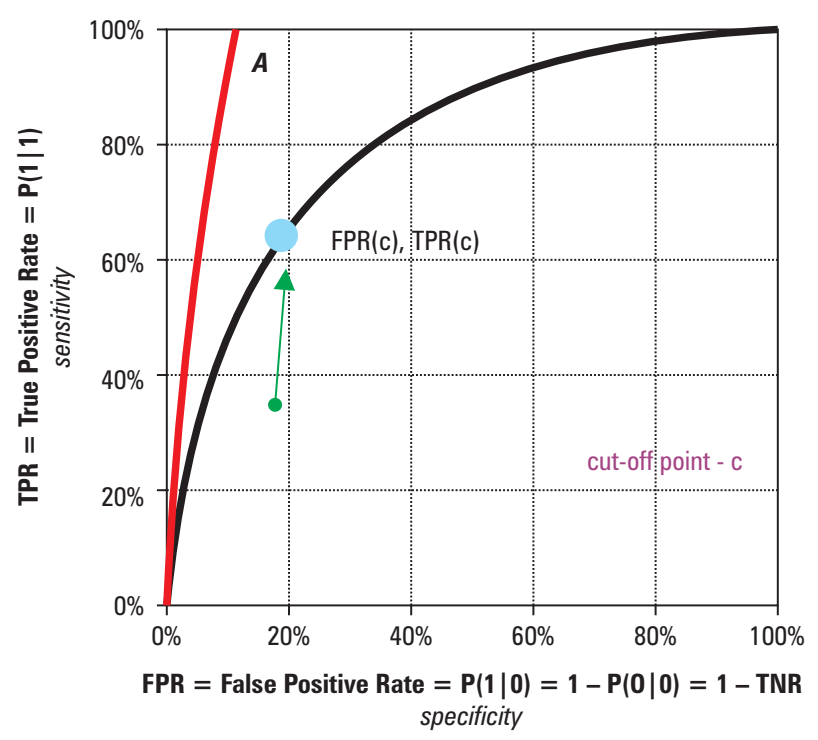

Source: Author's own study

Fig. 3. The ROC (Receiver Operating Characteristic) curve is a tool for assessing the correctness of the classifier. It provides a combined description of its sensitivity (here: the specialist's ability to detect all pathologies in images of a given quality) and specificity (here: the incorrectness of the detection process). The ideal of the test (in this case, the theoretical quality - interpretational unambiguity of the image), translates to the sensitivity of 100 per cent and inaccuracy of 0 per cent. We should strive for the situation where the image after filtration should possess the highest sensitivity and provide the least inaccuracy (specificity) compared to the source image (curve $A$ ). This method of supporting the decision-making system is widely used in various applications, including medical diagnostics. The equilibrium point represents the cut-off point for which the classifier achieves the balance where sensitivity $=$ specificity.

We build filters by selecting coefficients in the matrix and their values. Image filtering allows us to improve the image quality. Thus, depending on the type of filter used, we can manipulate the brightness level of images, we are able to sharpen or smoothen the edges of the objects, and introduce many other changes, which make it easier for us to read information from the image - therefore, that information becomes more legible to us.

In the image filtering process, we apply filters to images, which can be saved in the form of matrices. In the latter, we enter the coefficients we selected that characterize individual types of filters.

Among the manifold types of filters - for instance, low-pass filters, high-pass filters, contour filters, or Laplace filters - it is the latter that deserve our particular attention. They were applied in the ILWIS system, borrowed from the GIS environment (Fig. 4) [Jankowicz 2011]. Laplace filters, which are omnidirectional filters, constitute an inter- 
esting type - they are also the kind of filters used to detect edges in images. However, they differ from others in that they work in all directions, while detecting edges; also, in the end result, they produce sharp edges.

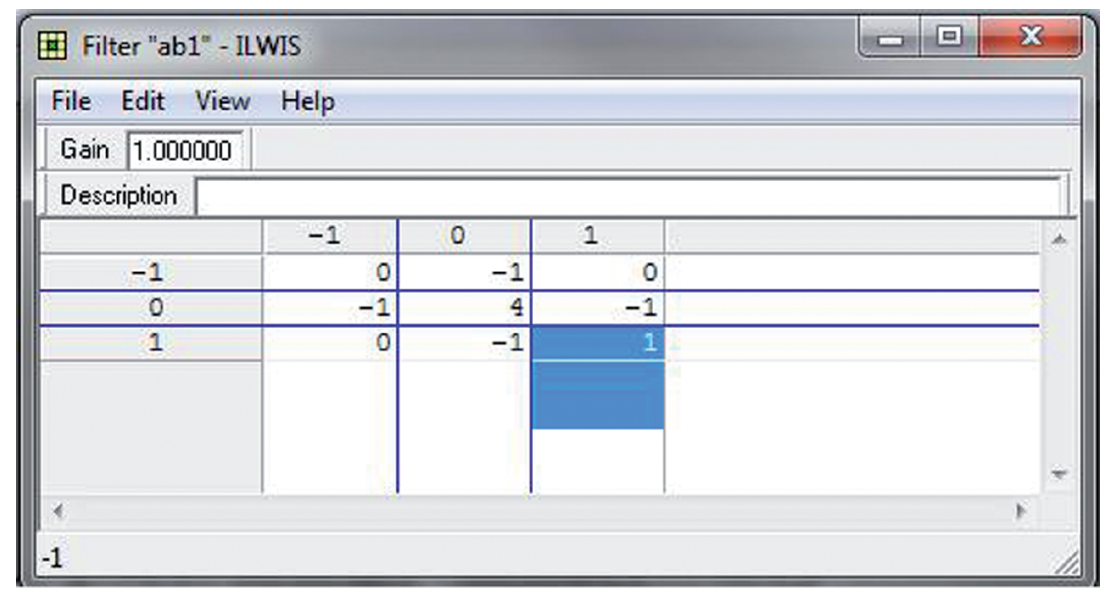

Source: Author's own study

Fig. 4. Application of one of Laplace's filters in the ILWIS software

The following are examples of Laplace's filters (A, B, C), whose effect shown visually and empirically proven represents the optimal impact on the process of detecting image structures:

A

\begin{tabular}{|c|c|c|}
\hline 0 & -1 & 0 \\
\hline-1 & 4 & -1 \\
\hline 0 & -1 & 0 \\
\hline
\end{tabular}

B

\begin{tabular}{|c|c|c|}
\hline-1 & -1 & -1 \\
\hline-1 & 8 & -1 \\
\hline-1 & -1 & -1 \\
\hline
\end{tabular}




\begin{tabular}{|c|c|c|}
\hline 1 & -2 & 1 \\
\hline-2 & 4 & -2 \\
\hline 1 & -2 & 1 \\
\hline
\end{tabular}

Returning to medicine, examples of proprietary applications of various types of edge filters in diagnostic medical imaging and the effects of their operation are further presented, partly based on the theory also described in foreign literature, such as Visualization in Medicine: Theory, Algorithms, and Applications [Preim and Bartz 2007].

In the photograph (Fig. 5), three measurement lines are shown, and the neck fold translucency test (the shortest visible NT line) can be seen. This is one of the most important parameters assessed during foetal ultrasound (USG) scan. It shows the swelling of the subcutaneous tissue around the nape of the neck. The increased value of this parameter often occurs in syndromes caused by chromosomal aberrations, such as Down syndrome, Edward syndrome, or Turner syndrome. The image below shows that this parameter to be correct.
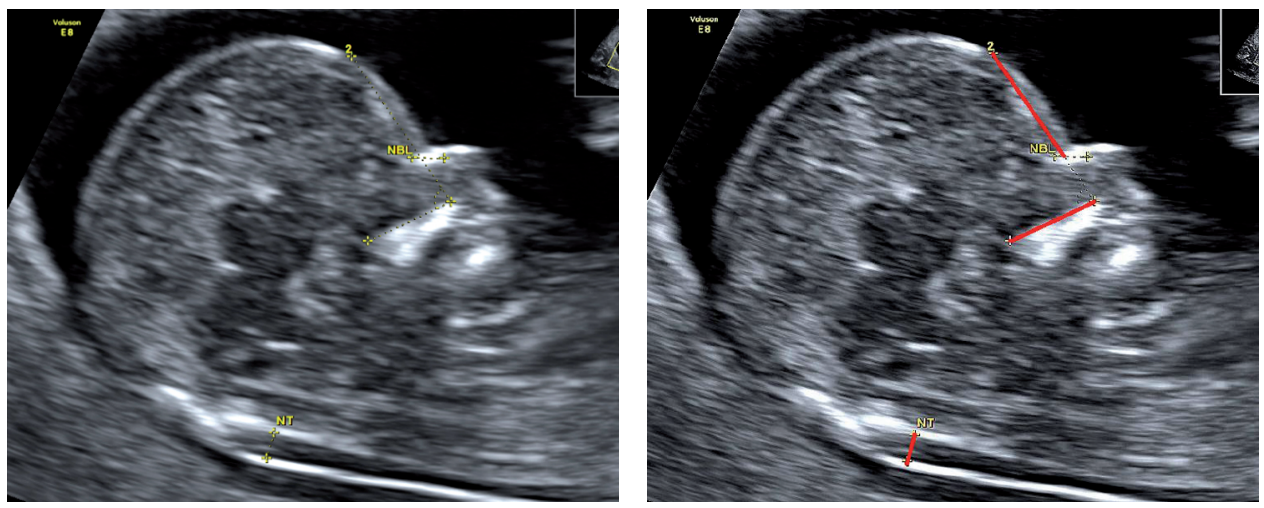

Source: Author's own materials

Fig. 5. Image from an NT scan before and after image filtering

The example above shows how edge sharpening filters work. Image filtering facilitates measurement of the swelling of the subcutaneous tissue near the nape of the neck with high accuracy.

The next example shows the effects of a high-pass "delete average" filter. It produces very satisfactory effects on the chest X-ray imaging. 

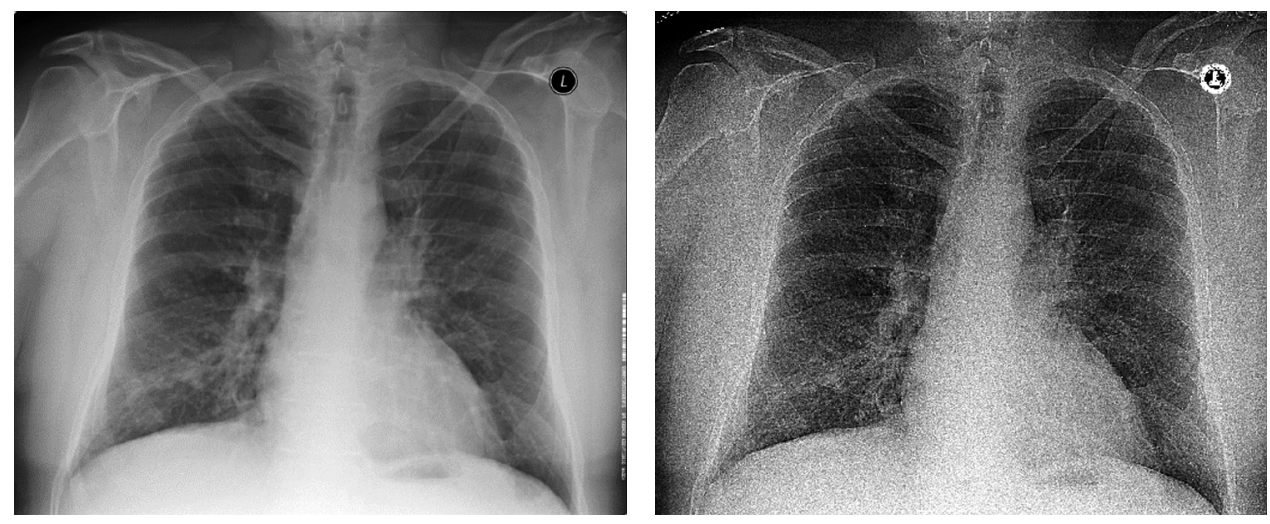

\begin{tabular}{|c|c|c|}
\hline-1 & -1 & -1 \\
\hline-1 & 9 & -1 \\
\hline-1 & -1 & -1 \\
\hline
\end{tabular}

Source: Author's own materials

Fig. 6. X-ray image of the chest before and after image filtering, along with the "filter".

The image after filtering has become much more sharp and clear. The bones of the chest, shoulders and ribcage are clearly outlined and well-defined (Fig. 6).

Setting the brightness level is a very important image filtering parameter. The example below shows the substantial effect that can be achieved by applying a high-pass filter to the image and brightening it significantly.

The images (Fig. 7) show the preoperative computed tomography of the head, with the finding of a nasal septum deviation. The author applied sharpening the edges and brightening the image, thanks to which the shape of the nose and the septum becomes much clearer. The structure of tomographic measuring systems, as well as image reconstruction, are widely described in the literature on the subject [Budzik et al. 2015, Budzik and Turek 2016], whereas the author focused on practical processing of the source image.

Further materials illustrate the effects of an ultrasound scan performed during pregnancy. The first image shows a human foetus. By sharpening and increasing the contrast, you can better visualize the elements of the face (Fig. 8).

Similar principles of ultrasound examination to the one mentioned above are applied to the determination of the sex of the baby, where, by analogy, sharpening the edge allows you to better see the details and increase the accuracy of the determination. 

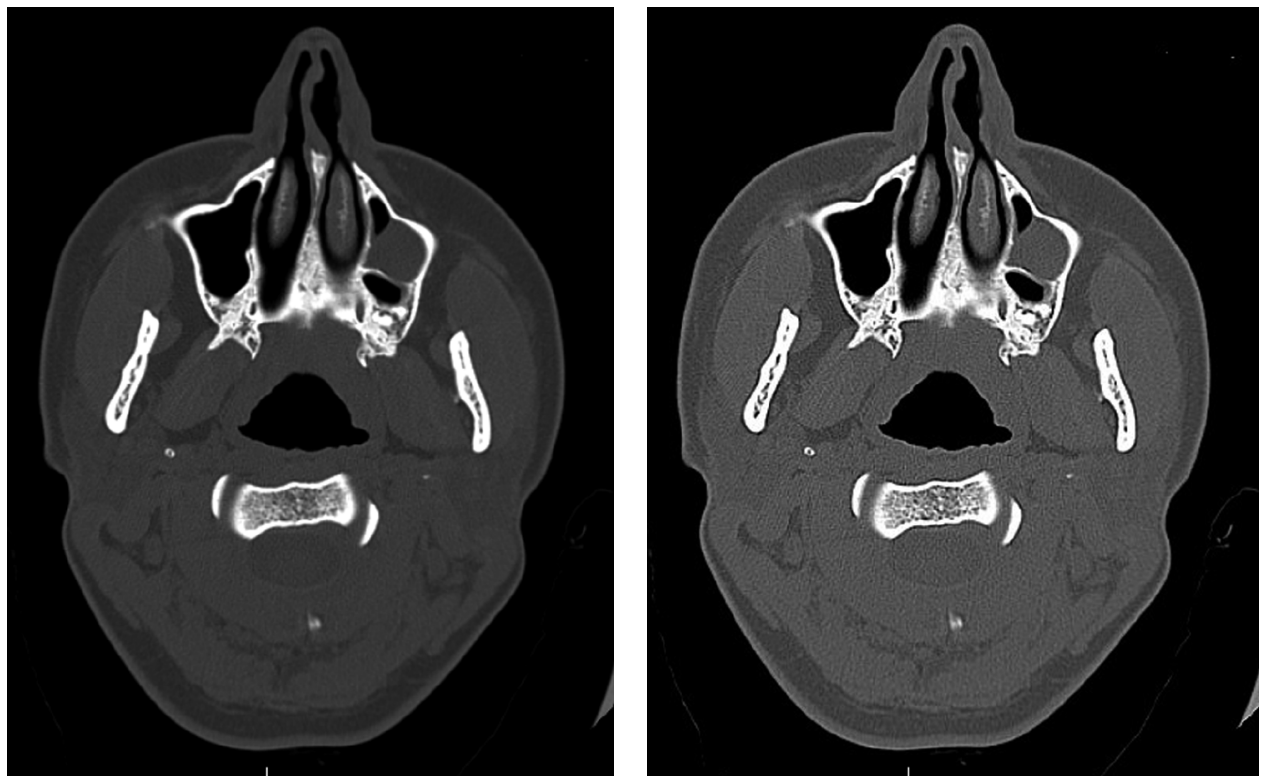

Source: Author's own materials

Fig. 7. CT scan of the head before and after image filtering
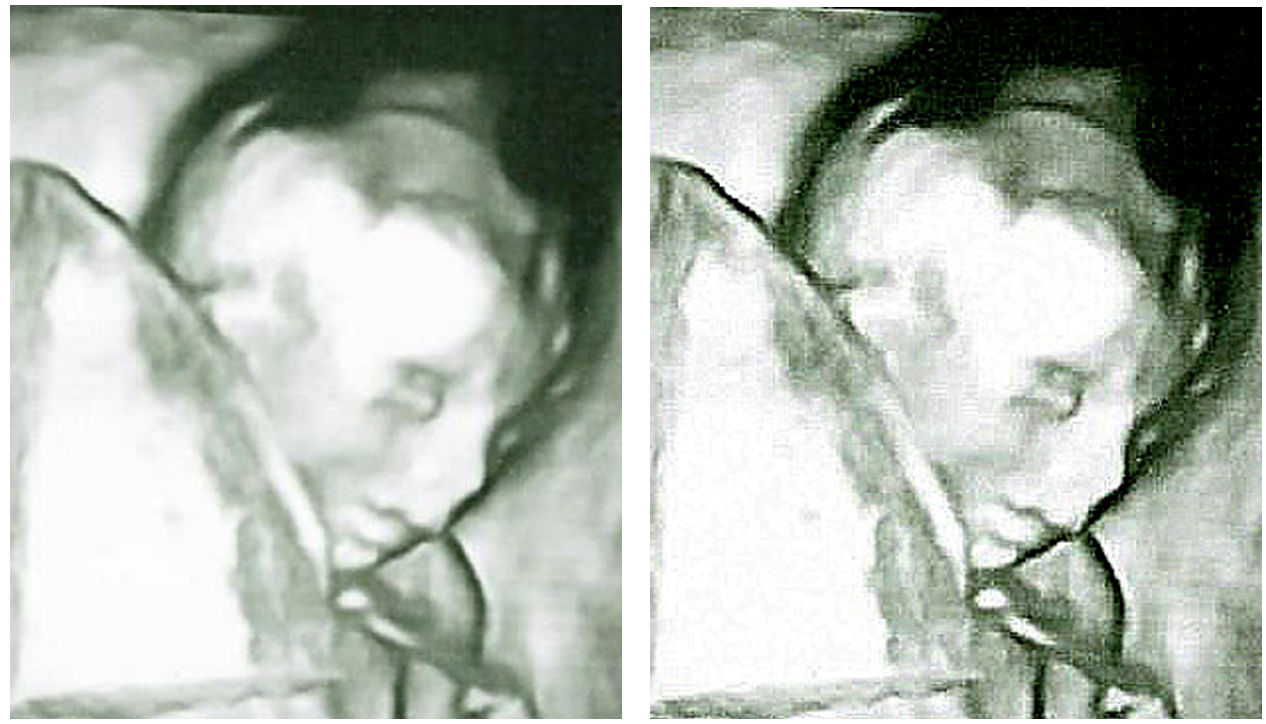

Source: Author's own materials

Fig. 8. USG image of the baby's face - before and after image filtering 
The next photo shows the result of the AC measurement, i.e. a test determining the size of the tummy circumference of the baby. It is measured at the height of the liver and stomach. It facilitates assessment of the harmony and proportionality of foetal development (Fig. 9).

In the provided example, the author applied sharpening the image with an edge filter, thanks to which we can check whether the measurement was accurately carried out during the test.
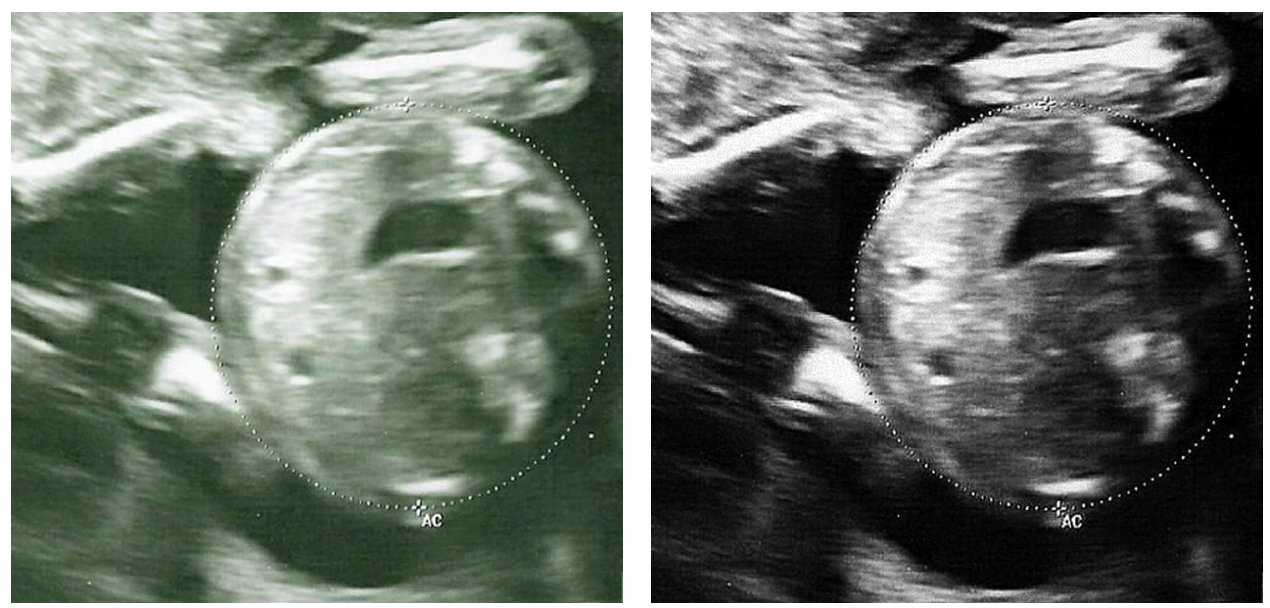

Source: Author's own materials

Fig. 9. Result of the AC measurement in ultrasound scan - before and after image filtering
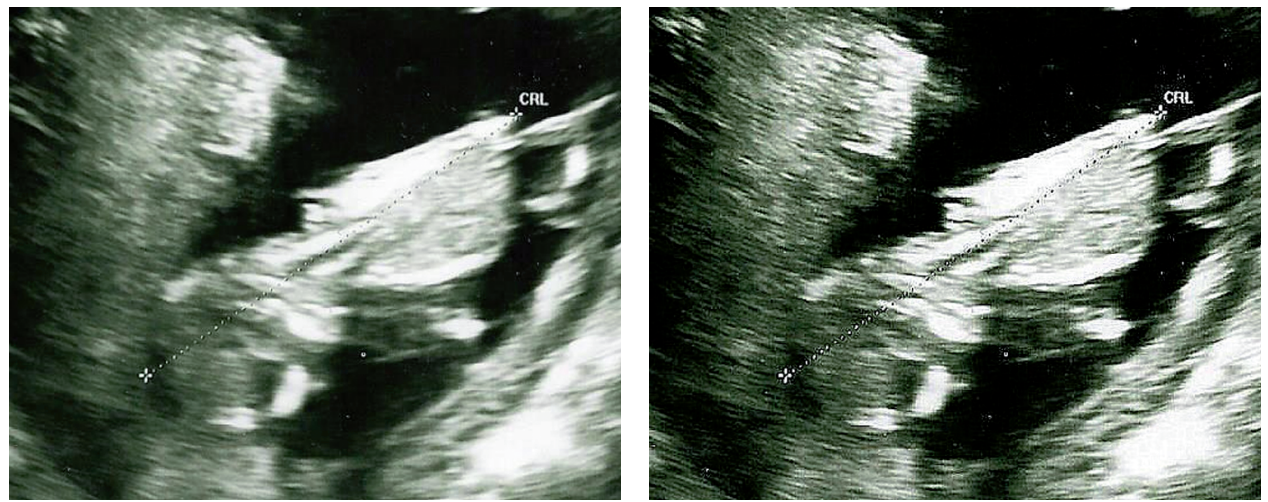

Source: Author's own materials

Fig. 10. Result of the foetal parietal distance measurement (between the two marks along the dotted line, marked in the image as CRL) - ultrasound scan before and after image filtering 
In Figure 10, the result of the CRL test is shown, i.e. the foetal parietal distance test. This is the parameter that tells the distance that the foetus has from the top of the head to the lower edge of the buttocks. This parameter is measured before the tenth week of pregnancy.

Thanks to edge sharpening and darkening of the image, it is possible to estimate the limits from which the measurement is made, because they are more clearly visible and well-defined.

MRI (Magnetic Resonance Imaging) is the main method for assessing brain structures, orbital contents, inner ear, cerebellum, bridge and medulla oblongata due to the complete absence of bone artefacts that are typical for computed tomography (Fig. 11). Magnetic resonance imaging is multifaceted, ensuring high spatial resolution. It enables the examination of intracranial vessels, which is especially important when suspecting aneurysmal and vascular lesions. In the case of diagnostic ambiguities regarding the assessment of computed tomography images, it is also recommended to perform a head MRI.
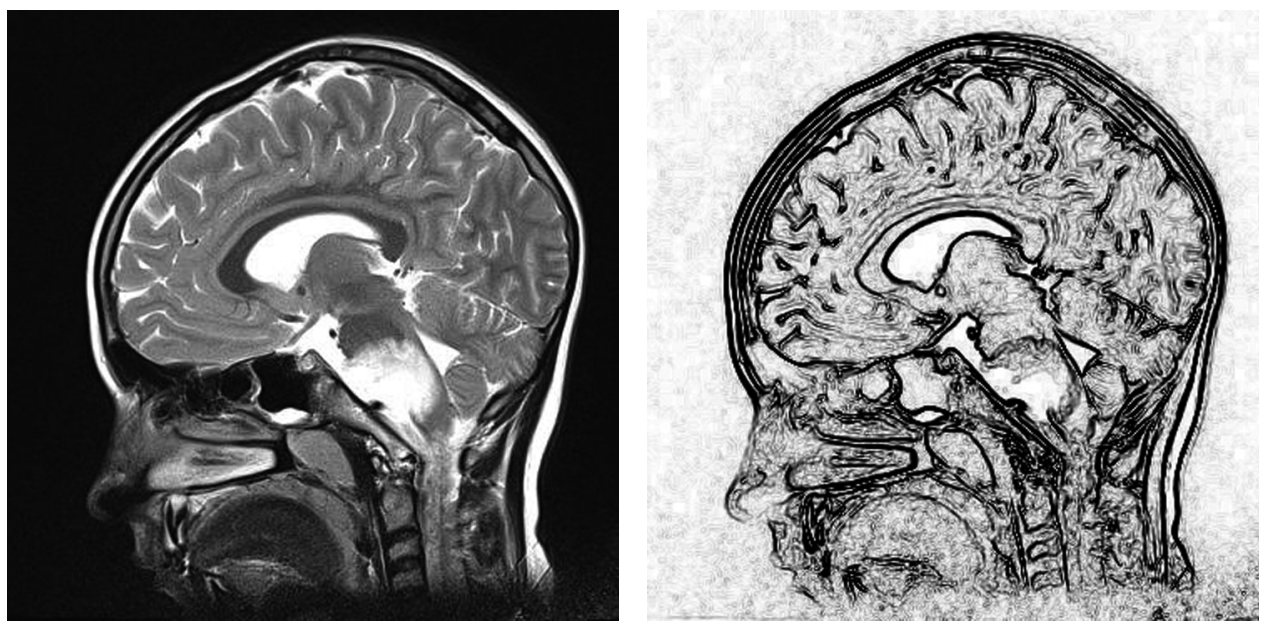

Source: Author's own materials

Fig. 11. Magnetic Resonance Imaging (MRI) of the head: before and after edge-detection image filtering

\section{Conclusions}

The author's experience indicates that in medical imaging, a group that is worth considering in the process of image filtering is the set of edge and contour filters, whose task is to sharpen the contours in the images, and improve their overall readability. This is also confirmed by the insights contained in the extensive literature on the subject. This is important for increasing the diagnostic reliability of images, 
associated with the detection of pathological symptoms, then making a diagnosis, or finally establishing targeted treatment. This, of course, is related to the fact that each imaging system has a time-frequency function that determines the limit frequency, allowing a specific level of detail in the description of information about the structures shown in the image.

The sub-pixel edge detection known from the literature increases accuracy and works well in technical structures with their characteristic regularity of shape, (such as in the approximation of edges mentioned earlier), while in living organisms there are no regular structures, and the use of this type of methods is more complex and requiring the appropriate selection of the fitting curve.

Therefore, the methods of improving and facilitating the reading of medical imaging research results are so helpful - image filtering undoubtedly being one of those methods - whereas the process of developing systems and applications of new filters is on-going and shall continue uninterrupted process in the near future for their continuous improvement.

Within the confines of this article it is impossible to show the virtually unlimited possibilities offered by the use of filters in medical imaging, or to illustrate the huge statistical material that would have to be included in the study on the accuracy of detection of pathological structures, taking into account different profiles of specialists (medical diagnosticians) in terms of their ability to detect all pathologies in images of a given quality (so-called "sensitivity") comparatively on source images and on their counterparts after filtration, while avoiding interpretation suggestions and bias - hence the author limited the discussion to selected examples only, while taking into account consultations with specialists from medical industry.

\section{References}

Bołdak C. 2008. Cyfrowe przetwarzanie obrazów.

Budzik G., Dziubek T., Turek P. 2015. Budowa tomograficznych systemów pomiarowych. Problemy Nauk Stosowanych, 3, 5-15.

Budzik G., Turek P. 2016. Proces rekonstrukcji obrazów tomograficznych. Problemy Nauk Stosowanych, 4, 57-64.

Butowtt J., Kaczyński R. 2003. Fotogrametria.

Dorozhynskyy O., Tukaj R. 2009. Fotogrametria. Wyd. Politechniki Lwowskiej, Lwów.

Jankowicz B. 2011. Technika multispektralna w teledetekcji. Wydawnictwo UR w Krakowie, Kraków.

Kędzierski M. 2002.Wykorzystanie analizy falkowej w procesie filtracji obrazów cyfrowych. AFKiT, 12a.

Mikrut S. 2009. Przydatność algorytmów podpikselowej detekcji cech w wybranych zagadnieniach fotogrametrycznych. AFKiT, 19.

Nieniewski M., Zajączkowski P. 2015. Real-Time USG Image Enhancement by Forward-Backward Diffusion. Springer.

Periasamy S. 1996. Detection of microcalcification in mammograms using hexagonal wavelets.

Preim B., Bartz D. 2007. Visualization in Medicine: Theory, Algorithms, and Applications. TheMorgan Kaufmann Series in Computer Graphics. 
Pyka K. 2005. Uwarunkowania fizjologiczne i techniczne wpływające na percepcję obrazu obserwowanego na ekranie monitora - Physiological and technical conditions, influencing perception of the monitor picture. Roczniki Geomatyki, 3, 1, 131-137, Polskie Towarzystwo Informacji Przestrzennej.

Pyka K. 2007. Zastosowanie transformacji falkowej do detekcji i usuwania szumów z danych rastrowych i pseudo-rastrowych - The use of wavelets in noise detection and removal from raster and pseudo-raster data. W: Geoinformatyka - badania, zastosowania i kształcenie. IV Ogólnopolskie Sympozjum Geoinformacyjne, Dobczyce k. Krakowa, 11-13 października 2007, red. B. Hejmanowska, M. Borowiec. Polskie Towarzystwo Fotogrametrii i Teledetekcji, 65-66.

Pyka K. 2011. Wykorzystanie transformacji falkowej do oceny spadku jakości radiometrycznej w procesie mozaikowania ortofotomapy - The use of wavelets for evaluation of loss in radiometric quality in the orthophoto mosaicking process. Biuletyn Wojskowej Akademii Technicznej, 60, 3, 353-364.

Pyka K. 2012. Noise detection in the photogrammetric images using wavelets. Journal of Earth Science and Engineering, 2, 2, 105-111.

Sayood K. 2002. Kompresja danych - wprowadzenie. RM, Warszawa.

Shuler S., Laine A. 2003. Hexagonal wavelet processing of digital mammography.

Soja J. et al. 2009. The Use of Endobronchial Ultrasonography in Assessment of Bronchial Wall Remodeling in Patients With Asthma. Elsevier.

Soja J., Łoboda P., Mikrut S., Ćmiel A., Gross-Sondej I., Górka K., Kasper Ł., Andrychiewicz A., Pulka G., Reid M., Sładek K. 2015. Assessment of remodeling in chronic obstructive pulmonary disease using imaging methods. Polskie Archiwum Medycyny Wewnętrznej, $125,9,659-664$.

Tadeusiewicz R., Zaremba-Śmietański J. 2011. Pozyskiwanie obrazów medycznych oraz ich przetwarzanie, analiza, automatyczne rozpoznawanie i diagnostyczna interpretacja. Wydawnictwo Studenckiego Towarzystwa Naukowego, Kraków.

www.doz.pl

https://mathspace.pl/

http://astrophysics.fic.uni.lodz.pl/medtech/dodatki/metpo.html

\author{
Dr inż. Bogdan Jankowicz \\ Uniwersytet Rolniczy w Krakowie \\ Katedra Geodezji Rolnej, Katastru i Fotogrametrii \\ ul. Balicka 253a, 30-198 Kraków \\ e-mail: rmjankow@cyf-kr.edu.pl \\ ORCID: 0000-0003-1603-0864
}

